\title{
Photodynamic Therapy as an adjunct in the Treatment of Medication-Related Osteonecrosis of the Jaw: A Case Report
}

\author{
Marcelo Vieira da Costa Almeida ${ }^{\circledR}$, Antonio C. Moura ${ }^{1}$, Lúcia Santos ${ }^{1}$, Luciana Gominho ${ }^{2^{\circledR}}$, Ully Dias \\ Nascimento Távora Cavalcanti ${ }^{\mathbb{D}}$, Kaline Romeiro ${ }^{1 * \mathbb{D}}$ \\ ${ }^{1}$ Department of Oral Medicine, Real Hospital Português de Beneficência em Pernambuco, 4760 - Paissandu, 52010-075, \\ Recife - PE, Brazil \\ ${ }^{2}$ Department of Restorative Dentistry, Universidade Federal da Paraíba - UFPB, s/n, Cidade Universitária - João Pessoa, \\ 58051-900, PB, Brazil
}

\section{*Correspondence to}

Kaline Romeiro, Department of

Oral Medicine, Real Hospital Português de Beneficência em Pernambuco, 4760 - Paissandu, 52010-075, Recife - PE, Brazil Email: kaline_rote@hotmail.com

Published online March 8, 2021

\begin{abstract}
Introduction: Medication-related osteonecrosis of the jaw (MRONJ) corresponds to an adverse effect of the use of drugs such as bisphosphonates and denosumab. This condition is often associated with pain, infection, purulent secretion, paraesthesia, tooth mobility and halitosis, decreasing the patient's quality of life. The management of MRONJ tends to be conservative, through the guidance of oral hygiene, antibiotic therapy and mouthwashes. However, the use of antimicrobial photodynamic therapy (aPDT) has shown promise in the treatment of these injuries. The purpose of this article is to report a case of MRONJ treatment associated with aPDT.

Case Report: A 75-year-old patient, with a history of breast cancer and use of intravenous Zoledronic Acid, presented with bilateral MRONJ lesions in tuberosity on the right and left sides. Treatment was conservatively instituted with the use of aPDT as an adjuvant. After 12 aPDT sessions, complete regression of the lesion was observed. However, after two weeks, the presence of a new lesion was noted, this time in the anterior region of the maxilla. The same protocol previously established was followed and after two aPDT sessions, the patient returned with complete lesion regression.

Conclusion: The use of aPDT may represent an important adjuvant within a set of clinical protocols in the treatment of MRONJ.

Keywords: Low-level laser therapy; MRONJ; Photodynamic therapy; Photobiomodulation; Bisphosphonates.
\end{abstract}

\section{Introduction}

Medication-related osteonecrosis of the jaw (MRONJ) is defined as exposed bone or bone that can be probed through an intraoral or extraoral fistula in the maxillofacial region and that persists for eight weeks in a patient who has received an antiresorptive agent or angiogenic inhibitor, without a history of head and neck radiation. ${ }^{1,2}$

The first descriptions of MRONJ were published in 2003, which occurred after intravenous treatment with nitrogen-containing bisphosphonates. ${ }^{3}$ Thus, the term osteonecrosis of the jaws induced by bisphosphonate (BRONJ) was inserted in scientific circles as an undesirable effect of the medication. ${ }^{4}$ In 2010 , osteonecrosis of the jaw was described in patients using denosumab. ${ }^{5}$ Therefore, the emphasis on the use of the term MRONJ instead of bisphosphonate-related osteonecrosis of the jaw (BRONJ) is based on the information that medications other than bisphosphonates can also contribute to the development of necrosis in the jaws. ${ }^{6,7}$

The risk of developing MRONJ depends on exposure to medication during treatment. More than $90 \%$ of cases occur in cancer patients with bone metastases receiving high-dose drugs. ${ }^{1,8}$ These patients have a high risk of developing skeletal complications, such as bone fractures, which can lead to decreased quality of life. ${ }^{9,10}$ Antiresorptive agents are known to decrease the risk of these events, with Bisphosphonates and denosumab being two of these drugs. ${ }^{11}$

Several factors can trigger the appearance of MRONJ, such as tooth extraction, prosthetic trauma, and periodontal diseases, among others. ${ }^{12}$ Therefore, it is important that dental surgeons are aware of the main signs and symptoms of osteonecrosis, which include exposed necrotic bone, pain, infections such as fistula, edema, purulent discharge, paraesthesia in the lower lip

Please cite this article as follows: Almeida MVC, Moura AC, Santos L, Gominho L, Cavalcanti UDNT, Romeiro K. Photodynamic therapy as an adjunct in the treatment of medication-related osteonecrosis of the jaw: a case report. J Lasers Med Sci. 2021;12:e12. doi:10.34172/ jlms.2021.12. 
or chin, tooth mobility and halitosis. ${ }^{13,14}$ Such symptoms can be constant or cyclical, and can affect daily activities such as eating, drinking and talking difficult, decreasing the patient's quality of life. ${ }^{15}$ The management of patients with osteonecrosis tends to be conservative, favoring the control of infections, bone necrosis and pain. ${ }^{16,17}$ Thus, they include oral hygiene guidelines, use of mouthwashes and antibiotics. ${ }^{18}$ Surgical interventions can be used if MRONJ shows persistent symptoms even after initial conservative treatment or affects function. ${ }^{19}$

However, the growing number of antibiotic-resistant microorganisms requires the development of alternative therapies. ${ }^{20}$ Antimicrobial photodynamic therapy (aPDT) is known for its activity on microorganisms reported in several in vitro and in vivo studies ${ }^{20,21}$ and can be promising in the treatment of MRONJ. ${ }^{22}$ This therapy has many advantages, including low cost, the absence of side effects and the impossibility of resistance acquired by bacteria. $^{23}$

The present study describes a case of MRONJ treated conservatively and with the use of aPDT as an adjuvant in patients with a history of zoledronic acid administration.

\section{Case Report}

A 75-year-old woman, with a history of breast cancer and use of intravenous Zoledronic Acid, arrived at the dental office complaining of upper jaw discomfort. On intraoral clinical examination, bilateral bone exposures compatible with osteonecrosis were observed in the regions of right and left tuberosity, also with the presence of purulent secretion (Figures $1 \mathrm{~A}$ and $1 \mathrm{~B}$ ). The patient used a removable partial denture, with instability and tipping motion. This may have been a factor of local trauma to the mucosa with the potential for triggering the observed injury.

Panoramic radiography showed the presence of radiolucent and radiopaque images suggesting bone sequestrations located on the maxillary tuberosity (right and left side) (Figure 3). Cone beam computed tomography images confirmed the presence of an osteolytic lesion in that area (Figures $4 \mathrm{~A}, 4 \mathrm{~B}$ and $4 \mathrm{C}$ ).

Initially, oral antibiotic therapy was recommended (clindamycin $300 \mathrm{mg}$ ) for 7 days and mouthwash with $0.12 \%$ chlorhexidine digluconate every 12 hours also for 7 days. Necrotic bone curettage was performed (Figure $1 \mathrm{C})$, and the removal of the removable partial denture posterior section was done with a carborundum disc to prevent trauma in the region of the lesions (Figures $1 \mathrm{D}$ and 1E). The aPDT sessions procedure was with a Hand Duo laser device (MM Optics LTDA) which has a continuous operation mode, a semiconductor light-emitting laser (gaAIAs and InGaAIP), a fixed power of $100 \mathrm{~mW}$, and a spot of $0.03 \mathrm{~cm}^{2}$. The red wavelength $(\lambda 660 \mathrm{~nm})$, for 90 seconds, with the spot in contact with the injury provided 9 J of energy. The methylene blue gel - $0.01 \%$ (Chimiolux DMC) was used as a photosensitizing agent. The preirradiation time was set at 5 minutes. Then, the area was rinsed for 1 minute using sterile saline solution in order to

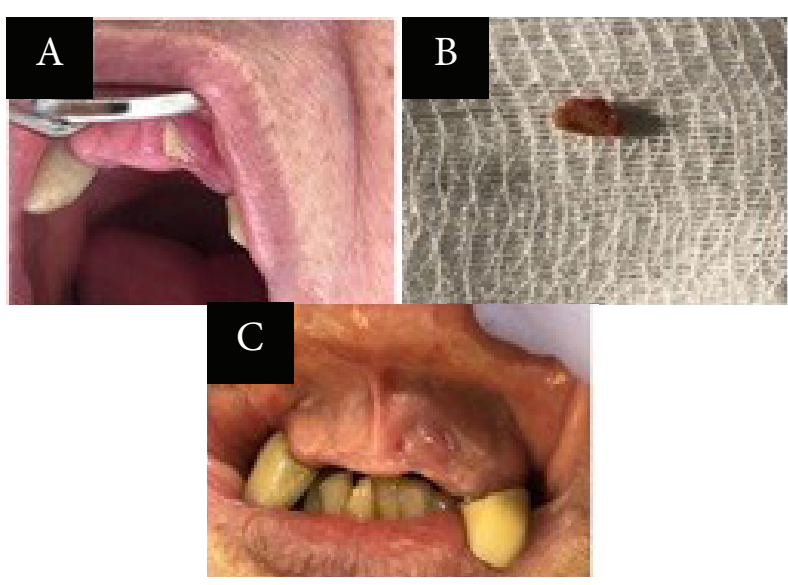

Figure 2. Initial Clinical Aspect on the Anterior Region of the Maxilla (A); Debridement of the Necrotic Bone (B); Clinical Aspect After Two Sessions (C).

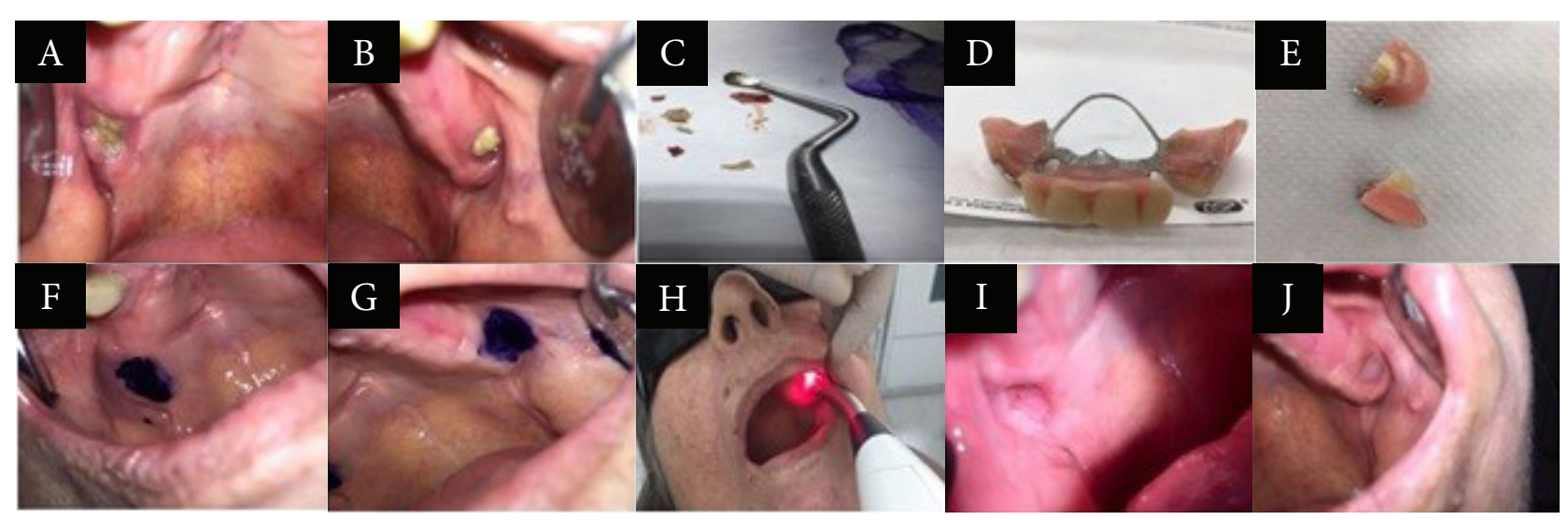

Figure 1. Initial Clinical Image Showing the Exposed Bone on the Right (A) and Left (B) Sides of the Tuberosity Region; Debridement of the Necrotic Bone Until Reaching the Clinically Vital Margin (C); Removal of the Removable Partial Denture Posterior Section (D and E); Methylene Blue Gel $0.01 \%$ and Pre-irradiation Time (F and G); Clinical Aspect After 12 Sessions on the Right (I) and Left (J) Sides of the Maxillary Arch. 


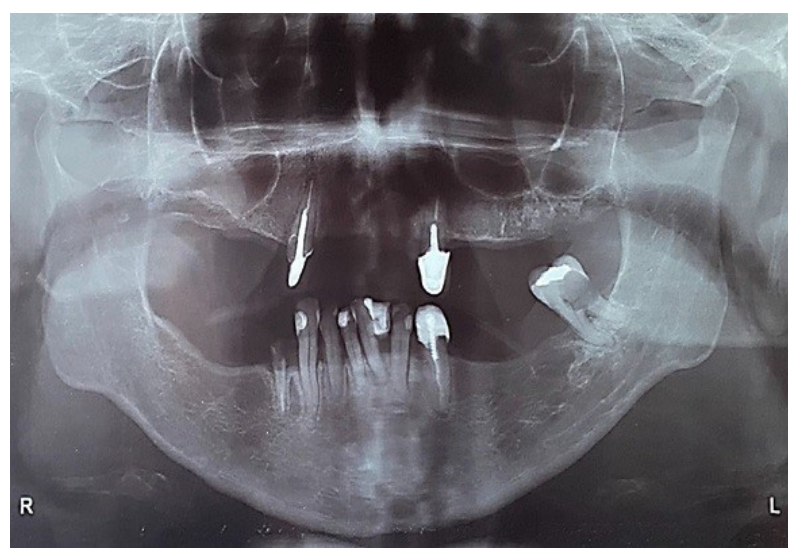

Figure 3. Bilateral Tuberosity Aspect on Panoramic Radiograph.

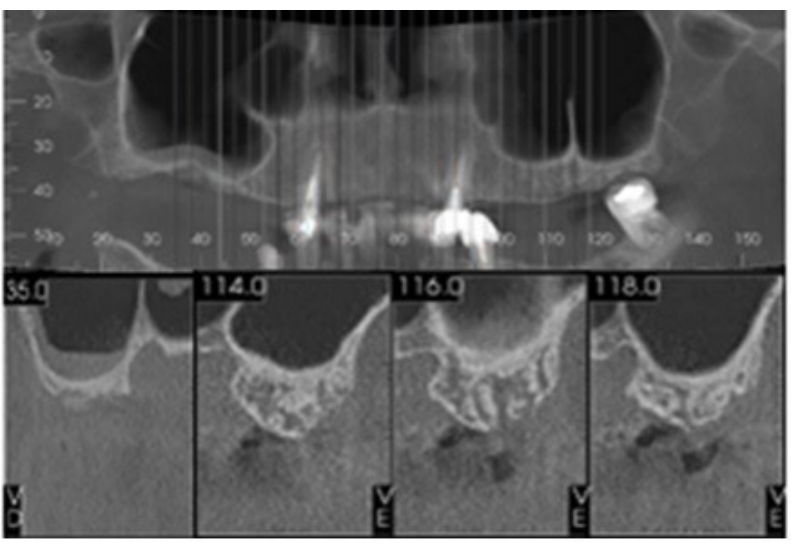

Figure 4. Cone Beam Computed Tomography Images Showing the Aspect of the Osteolytic Process on Maxillary Tuberosity (A). Right (B) and left (C, D, E) Sides.

wash out the excess of the photosensitizer. The intervals between each aPDT session were established in 48 hours (Figures 1F, 1G and 1H). Other laser specifications and irradiation protocols are described in Table 1.

After 12 aPDT sessions, complete regression of the lesion with an absence of painful symptoms or presence of purulent secretion was observed in the region (Figures 1I and 1J). However, after 2 weeks, a new lesion was observed, this time in the anterior region of the maxilla (Figure 2A). Therefore, it was recommended that the patient should not use the current prosthesis even compromising the aesthetic. Also, it was encouraged to start rehabilitating treatment with a more adequate prosthesis even compromising the aesthetics. The same protocol mentioned above was followed with antibiotic therapy, the curettage of necrotic bone (Figure 2B), mouthwashes with $0.12 \%$ chlorhexidine digluconate and the application of aPDT. However, after two sessions of aPDT and following all the care already mentioned, the patient returned with complete regression of the lesion (Figure 2C). At this time, the patient was encouraged to start rehabilitating treatment for the use of a well-adapted prosthesis.

After 24 months, the patient was asymptomatic, with no evidence of osteonecrosis and reporting improvement in quality of life.

\section{Discussion}

The osteonecrosis lesion reported in this article can be classified as stage two, which is characterized by the presence of necrotic bone or bone that can be probed through a fistula, associated with the infection, with pain and erythema in the exposed bone region, with or without purulent drainage. ${ }^{1}$ Therefore, the recommended treatment is symptomatic, using antibiotics orally and mouthwashes with antimicrobial action, pain control, debridement to relieve irritation in soft tissue and infection control. According to Heggendorn et $\mathrm{al},{ }^{24}$ the treatment of MRONJ is very difficult and there are still no fully resolving treatment protocols. In this context, aPDT was selected to be applied as an adjuvant treatment in this case.

The aPDT acts on exogenous photoreceptors, promoting the interaction of light with a photosensitizer, producing reactive oxygen species, which causes microbial reduction. ${ }^{25}$ In addition, there is evidence that aPDT has biomodulation activity in keratinocytes, fibroblasts, osteoclasts and angiogenesis improving tissue repair. ${ }^{26}$ Thus, the present data indicate that aPDT can be a useful therapy to treat oral infections. ${ }^{27}$

These properties highlighted above are of extreme importance especially when the use of local and/or systemic antibiotics becomes inefficient in eliminating

Table 1. Technical Parameters for the Reported Case

\begin{tabular}{|c|c|}
\hline Technical Parameters & aPDT \\
\hline Light source & Low-level diode laser \\
\hline Active medium & GaAlAs \\
\hline Wavelength & $660 \mathrm{~nm} \pm 10 \mathrm{~nm}$ \\
\hline Power output & $0.1 \mathrm{~W}( \pm 20 \%), \mathrm{CW}$ \\
\hline $\begin{array}{l}\text { Irradiation mode and frequency of } \\
\text { treatment }\end{array}$ & $\begin{array}{c}\text { Contact, punctual, every other } \\
\text { day }\end{array}$ \\
\hline Model/Manufacturer & MMO Duo (MM Optics LTDA) \\
\hline Spot area & $0.03 \mathrm{~cm}^{2}$ \\
\hline $\begin{array}{l}\text { Exposure time per point/session/time } \\
\text { treatment per week }\end{array}$ & $90 \mathrm{~s}$ \\
\hline Number of points & 1 \\
\hline Energy per point & $9 \mathrm{~J}$ \\
\hline Energy per daily session & $9 \mathrm{~J}$ \\
\hline Dye/PIT & Methylene blue $0.01 \% / 5$ min \\
\hline Fluence per point & $300 \mathrm{~J} / \mathrm{cm}^{2}$ \\
\hline Total fluence in each session & $300 \mathrm{~J} / \mathrm{cm}^{2}$ \\
\hline Irradiance per point & $3.33 \mathrm{~W} / \mathrm{cm}^{2}$ \\
\hline Cumulative dose given & $108 \mathrm{~J} / \mathrm{cm}^{2}$ \\
\hline Total irradiation time & $1080 \mathrm{~s}$ \\
\hline
\end{tabular}


complex biofilm formation on the exposed bone of MRONJ. Aerobic and anaerobic bacterial pathogens, parasites, fungi, and viruses identified in MRONJ lesions are the targets of the reactive oxygen species released during the photochemical process of the aPDT.

Minamisako et $\mathrm{al}^{28}$ state in their study that aPDT appears to be a safe antimicrobial treatment that saves healthy tissues from the harmful effects of treatment, justifying its use in the treatment of MRONJ. This statement corroborates that of Eduardo et $\mathrm{al},{ }^{29}$ which says that the reports of the use of aPDT in MRONJ are promising, showing efficacy in reepithelization and bone repair.

In cancer patients and using zoledronic acid, the risk of developing MRONJ is approximately 1\% (100 cases per 10000 patients)..$^{16,30,31}$ This medication is widely used in cases of cancer with a high risk of bone metastasis, such as prostate, lung and breast cancers, ${ }^{30}$ as in the case of the patient reported in this study.

Several authors have established the trauma caused by poorly adapted prosthetic rehabilitation as a triggering factor for MRONJ..$^{12,18,32-37}$ It is important to note that the removal of the traumatic agent, represented by the dental prosthesis in the case described in this study, may have corresponded to an essential step in the remission of the MRONJ. Also, the use of $0.12 \%$ chlorhexidine, a cationic biguanide of broad bacterial spectrum, active against gram-positive, gram-negative and fungus bacteria, ${ }^{38}$ associated with the use of clindamycin, an antibiotic with good coverage for gram-positive and anaerobic bacteria, ${ }^{39}$ played a key role in the resolution of the case. However, it is possible that photodynamic therapy contributed to a faster repair of MRONJ since the remission of these cases tends to be slower without the use of this therapy.

\section{Conclusion}

The use of aPDT in MRONJ is still not widespread. However, the few studies available suggest that this therapy can represent an important adjuvant within a set of clinical protocols, as also observed in this case report. Randomized clinical trials should be carried out so aPDT benefit in the MRONJ treatment and its benefit in the treatment of these lesions could be evidenced with a greater scientific basis.

\section{Ethical Considerations}

Informed consent was obtained from the patient for publication of this report.

\section{Conflict of Interests}

The authors declare that there is no conflict of interest regarding the publication of this paper.

\section{References}

1. Ruggiero SL, Dodson TB, Fantasia J, Goodday R, Aghaloo
T, Mehrotra B, et al. American Association of Oral and Maxillofacial Surgeons position paper on medicationrelated osteonecrosis of the jaw--2014 update. J Oral Maxillofac Surg. 2014;72(10):1938-56. doi: 10.1016/j. joms.2014.04.031.

2. Khan A, Morrison A, Cheung A, Hashem W, Compston J. Osteonecrosis of the jaw (ONJ): diagnosis and management in 2015. Osteoporos Int. 2016;27(3):853-859. doi: 10.1007/ s00198-015-3335-3.

3. Marx RE. Pamidronate (Aredia) and zoledronate (Zometa) induced avascular necrosis of the jaws: a growing epidemic. J Oral Maxillofac Surg. 2003;61(9):1115-7. doi: 10.1016/ s0278-2391(03)00720-1.

4. Ruggiero SL, Mehrotra B, Rosenberg TJ, Engroff SL. Osteonecrosis of the jaws associated with the use of bisphosphonates: a review of 63 cases. J Oral Maxillofac Surg. 2004;62(5):527-34. doi: 10.1016/j.joms.2004.02.004.

5. Aghaloo TL, Felsenfeld AL, Tetradis S. Osteonecrosis of the jaw in a patient on denosumab. J Oral Maxillofac Surg. 2010;68(5):959-63. doi: 10.1016/j.joms.2009.10.010.

6. Aragon-Ching JB, Ning YM, Chen CC, Latham L, Guadagnini JP, Gulley JL, et al. Higher incidence of Osteonecrosis of the Jaw (ONJ) in patients with metastatic castration resistant prostate cancer treated with antiangiogenic agents. Cancer Invest. 2009;27(2):221-6. doi: 10.1080/07357900802208608.

7. Stopeck AT, Fizazi K, Body JJ, Brown JE, Carducci M, Diel I, et al. Safety of long-term denosumab therapy: results from the open label extension phase of two phase 3 studies in patients with metastatic breast and prostate cancer. Support Care Cancer. 2016;24(1):447-55. doi: 10.1007/ s00520-015-2904-5.

8. Otto S, Abu-Id MH, Fedele S, Warnke PH, Becker ST, Kolk A, et al. Osteoporosis and bisphosphonates-related osteonecrosis of the jaw: Not just a sporadic coincidence - A multi-centre study. J Craniomaxillofac Surg. 2011 Jun;39(4):272-7. doi: 10.1016/j.jcms.2010.05.009.

9. Coleman RE. Clinical features of metastatic bone disease and risk of skeletal morbidity. Clin Cancer Res. 2006;12(20 Pt 2):6243s-6249s. doi: 10.1158/1078-0432.CCR-06-0931.

10. Hernlund E, Svedbom A, Ivergård M, Compston J, Cooper C, Stenmark J, et al. Osteoporosis in the European Union: Medical management, epidemiology and economic burden: A report prepared in collaboration with the International Osteoporosis Foundation (IOF) and the European Federation of Pharmaceutical Industry Associations (EFPIA). Arch Osteoporos. 2013;8(1-2):136. doi: 10.1007/ s11657-013-0136-1.

11. Loyson T, Van Cann T, Schöffski P, Clement PM, Bechter $\mathrm{O}$, Spriet I, et al. Incidence of osteonecrosis of the jaw in patients with bone metastases treated sequentially with bisphosphonates and denosumab. Acta Clin Belg. 2018;73(2):100-109. doi: 10.1080/17843286.2017.1348001.

12. Fassio A, Bertoldo F, Idolazzi L, Viapiana O, Rossini M, Gatti D. Drug-induced osteonecrosis of the jaw: the state of the art. Reumatismo. 2017;69(1):9-15. doi: 10.4081/ reumatismo.2017.983.

13. Ficarra G, Beninati F. Bisphosphonate - related osteonecrosis of the jaws: the point of view of the oral pathologist. Clin Cases Miner Bone Metab. 2007;4(1):53-7.

14. Saad F, Brown JE, Van Poznak C, Ibrahim T, Stemmer SM, 
Stopeck AT, et al. Incidence, risk factors, and outcomes of osteonecrosis of the jaw: Integrated analysis from three blinded active-controlled phase III trials in cancer patients with bone metastases. Ann Oncol. 2012;23(5):1341-1347. doi: 10.1093/annonc/mdr435.

15. Patel V, Mansi J, Ghosh S, Kwok J, Burke M, Reilly D, et al. MRONJ risk of adjuvant bisphosphonates in early stage breast cancer. Br Dent J. 2018;224(2):74-79. doi: 10.1038/ sj.bdj.2017.1039.

16. QiWX, Tang LN, He AN, Yao Y, Shen Z. Risk of osteonecrosis of the jaw in cancer patients receiving denosumab: a metaanalysis of seven randomized controlled trials. Int J Clin Oncol. 2014;19(2):403-10. doi: 10.1007/s10147-013-05616.

17. Rosella D, Papi P, Giardino R, Cicalini E, Piccoli L, Pompa G. Medication-related osteonecrosis of the jaw: Clinical and practical guidelines. J Int Soc Prev Community Dent. 2016;6(2):97-104. doi: 10.4103/2231-0762.178742.

18. Zebic L, Patel V. Preventing medication-related osteonecrosis of the jaw. BMJ. 2019;365:11733. doi: 10.1136/bmj.11733.

19. Yarom N, Shapiro CL, Peterson DE, Van Poznak CH, Bohlke K, Ruggiero SL, et al. Medication-related osteonecrosis of the jaw: MASCC/ISOO/ASCO clinical practice guideline. J Clin Oncol. 2019;37(25):2270-2290. doi: 10.1200/JCO.19.01186.

20. O’Riordan K, Akilov OE, Hasan T. The potential for photodynamic therapy in the treatment of localized infections. Photodiagnosis Photodyn Ther. 2005;2(4):24762. doi: 10.1016/S1572-1000(05)00099-2.

21. Bisland SK, Burch S. Photodynamic therapy of diseased bone. Photodiagnosis Photodyn Ther. 2006 Sep;3(3):147-55. doi: 10.1016/S1572-1000(06)00036-6.

22. de Castro MS, Ribeiro NV Jr, de Carli ML, Pereira AA, Sperandio FF, Hanemann JA. Photodynamically dealing with bisphosphonate-related osteonecrosis of the jaw: Successful case reports. Photodiagnosis Photodyn Ther. 2016;16:72-75. doi: 10.1016/j.pdpdt.2016.08.007.

23. Eduardo CP, Bello-Silva MS, Ramalho KM, Lee EMR, Aranha ACC. A terapia fotodinâmica como benefício complementar na clínica odontológica. Rev Assoc Paul Cir. 2015;69(3):226-35. [Portugue]

24. Heggendorn FL, Leite TC, Cunha KSG, Junior AS, Gonçalves LS, Da Costa KBFF, et al. Bisphosphonaterelated osteonecrosis of the jaws: Report of a case using conservative protocol. Spec Care Dentist. 2016;36(1):43-7. doi: $10.1111 / \mathrm{scd} .12143$.

25. Ribeiro GH, Minamisako MC, Rath IB da S, Santos AMB, Simões A, Pereira KCR, et al. Osteoradionecrosis of the jaws: case series treated with adjuvant low-level laser therapy and antimicrobial photodynamic therapy. J Appl Oral Sci. 2018;26:e20170172. doi: 10.1590/1678-77572017-0172.

26. de Freitas LF, Hamblin MR. Proposed Mechanisms of Photobiomodulation or Low-Level Light Therapy. IEEE J Sel Top Quantum Electron. 2016;22(3):7000417. doi:
10.1109/JSTQE.2016.2561201.

27. Núñez SC, Garcez AS, Kato IT, Yoshimura TM, Gomes L, Baptista MS, et al. Effects of ionic strength on the antimicrobial photodynamic efficiency of methylene blue. Photochem Photobiol Sci. 2014;13(3):595-602. doi: 10.1039/c3pp50325a.

28. Minamisako MC, Ribeiro GH, Lisboa ML, Mariela Rodríguez Cordeiro M, Grando LJ. Medication-related osteonecrosis of jaws: a low-level laser therapy and antimicrobial photodynamic therapy case approach. Case Rep Dent. 2016;2016:6267406. doi: 10.1155/2016/6267406.

29. Eduardo FP, Bezinelli LM, Correa L. Odontologia na Oncologia. 1st ed. São Paulo: Atheneu; 2019.

30. Patel V, Kelleher M, Sproat C, Kwok J, McGurk M. New cancer therapies and jaw necrosis. Br Dent $J$. 2015;219(5):203-7. doi: 10.1038/sj.bdj.2015.680

31. Scagliotti GV, Hirsh V, Siena S, Henry DH, Woll PJ, Manegold $C$, et al. Overall survival improvement in patients with lung cancer and bone metastases treated with denosumab versus zoledronic acid: Subgroup analysis from a randomized phase 3 study. J Thorac Oncol. 2012;7(12):1823-9. doi: 10.1097/JTO.0b013e31826aec2b.

32. Goodday RH. Preventive Strategies for Patients at Risk of Medication-related Osteonecrosis of the Jaw. Oral Maxillofac Surg Clin North Am. 2015;27(4):527-36. doi: 10.1016/j.coms.2015.06.006.

33. Grisar K, Schol M, Schoenaers J, Dormaar T, Coropciuc $\mathrm{R}$, Vander Poorten V, et al. Osteoradionecrosis and medication-related osteonecrosis of the jaw: similarities and differences. Int J Oral Maxillofac Surg. 2016;45(12):15921599. doi: 10.1016/j.ijom.2016.06.016.

34. Otto S, Pautke C, Van den Wyngaert T, Niepel D, Schiødt M. Medication-related osteonecrosis of the jaw: Prevention, diagnosis and management in patients with cancer and bone metastases. Cancer Treat Rev. 2018;69:177-187. doi: 10.1016/j.ctrv.2018.06.007.

35. de Sales Lima MV, Rizzato J, Gracindo Marques DV, Kitakawa D, da Silva Peralta F, Prado Scherma A, et al. Denosumab Related Osteonecrosis of Jaw: a Case Report. J Oral Maxillofac Res. 2018;9(4):e5. doi: 10.5037/ jomr.2018.9405.

36. Kuroshima S, Sasaki M, Sawase T. Medication-related osteonecrosis of the jaw: A literature review. J Oral Biosci. 2019;61(2):99-104. doi: 10.1016/j.job.2019.03.005.

37. Nicolatou-Galitis O, Schiødt M, Mendes RA, Ripamonti C, Hope S, Drudge-Coates L, et al. Medication-related osteonecrosis of the jaw: definition and best practice for prevention, diagnosis, and treatment. Oral Surg Oral Med Oral Pathol Oral Radiol. 2019;127(2):117-135. doi: 10.1016/j.oooo.2018.09.008.

38. Andrade IP, Xavier KBC, Nunes APF, Fardin RF. Concentração inibitória mínina de antissépticos bucais em microorganismos da cavidade oral. RBPS [Internet]. 2011 Sep 10 [cited 2021Feb 23]; Available from: https:// periodicos.ufes.br/rbps/article/view/1761.

39. Bulloch MN, Baccas JT, Arnold S. Clindamycin-induced hypersensitivity reaction. Infection. 2016;44(3):357-9. doi: 10.1007/s15010-015-0826-2. 